\title{
Architecture of divergent flagellar promoters controlled by CtrA in Rhodobacter sphaeroides
}

\author{
Anet Rivera-Osorio ${ }^{1}$, Aurora Osorio ${ }^{1}$, Sebastian Poggio ${ }^{1}$, Georges Dreyfus ${ }^{2^{*}}$ and Laura Camarena ${ }^{1 *}$ (D)
}

\begin{abstract}
Background: Rhodobacter sphaeroides has two sets of flagellar genes, fla1 and fla2, that are responsible for the synthesis of two different flagellar structures. The expression of the fla2 genes is under control of CtrA. In several a-proteobacteria CtrA is also required for the expression of the flagellar genes, but the architecture of CtrAdependent promoters has only been studied in detail in Caulobacter crescentus. In many cases the expression of fla genes originates from divergent promoters located a few base pairs apart, suggesting a particular arrangement of the cis-acting sites.
\end{abstract}

Results: Here we characterized several control regions of the $R$. sphaeroides fla2 genes and analyzed in detail two regions containing the divergent promoters flgB2p-flil2p, and fliL2p-fliF2p. Binding sites for CtrA of these promoters were identified in silico and tested by site directed mutagenesis. We conclude that each one of these promoter regions has a particular arrangement, either a single CtrA binding site for activation of fliL $2 p$ and flif $2 p$, or two independent sites for activation of flgB2p and flil2p. ChIP experiments confirmed that CtrA binds to the control region containing the flgB2 and flil2 promoters, supporting the notion that CtrA directly controls the expression of the fla 2 genes. The flgB and flil genes are syntenic and show a short intercistronic region in closely related bacterial species. We analyzed these regions and found that the arrangement of the CtrA binding sites varies considerably.

Conclusions: The results in this work reveal the arrangement of the fla2 divergent promoters showing that CtrA promotes transcriptional activation using more than a single architecture.

Keywords: Rhodobacter sphaeroides, CtrA, Bacterial flagellum, Divergent promoters

\section{Background}

Many bacteria use rotating flagella for locomotion, the motor is embedded in the membrane and couples the influx of specific ions to the generation of rotational force. The bacterial flagellum can be divided in a basal body that includes the motor, a filament that acts as a propeller, and a universal joint also known as the hook which links the basal body and the filament. The basal body is the most complex structure that includes an axial rod and three or more rings, depending on the bacterial species. In Escherichia coli and Salmonella enterica, the basal body includes

\footnotetext{
* Correspondence: gdreyfus@ifc.unam.mx; rosal@unam.mx

${ }^{2}$ Instituto de Fisiología Celular, Universidad Nacional Autónoma de México, México City, México

'Instituto de Investigaciones Biomédicas, Universidad Nacional Autónoma de México, México City, México
}

the MS-, P- and L-rings. Flagellar biogenesis requires the expression of more than 40 genes, and the assembly of this structure proceeds outwardly from proximal to distal end $[1,2]$. In many bacterial species, the expression of the flagellar genes follows a hierarchical pattern with a variable number of tiers. Genes encoding the early components of the flagellar structure (basal body and export apparatus) are expressed under the control of a master activator protein placed at the top of the hierarchy. Frequently, along with the early genes, additional transcription factors are expressed that become active to transcribe the late genes in response to a signal that denotes that the early flagellar components have been assembled [3-5]. The flagellar gene expression regulatory hierarchies have been analyzed in different bacteria; in E. coli and S. enterica the transcriptional activator FlhD/FlhC is required to

(c) The Author(s). 2018 Open Access This article is distributed under the terms of the Creative Commons Attribution 4.0 International License (http://creativecommons.org/licenses/by/4.0/), which permits unrestricted use, distribution, and 
express the early flagellar genes (Class II) which encode the proteins required to form the basal body and the hook. The genes encoding the sigma factor FliA and its specific anti-sigma factor, FlgM also belong to this class. Once the basal body and the hook are assembled, FlgM is exported out of the cell and FliA associates with the core RNA polymerase to recognize class III promoters [5]. In other $\gamma$-proteobacteria (i.e. Vibrio, Pseudomonas), the flagellar gene expression hierarchy shows a different architecture and special features. In several species the sigma factor RpoN together with an activator protein promote the expression of the early flagellar genes, and the late genes are dependent on FliA. In these systems the expression of late flagellar genes also requires the export of FlgM [3]. Only a few examples of flagellar gene expression hierarchies have been reported for $\alpha$ proteobacteria; nonetheless, a substantial variation in the control networks is evident. For instance, in Sinorhizobium meliloti two members of the LuxR family, VisN and VisR [6], bring about the expression of rem, which encodes an OmpR-like transcriptional activator that promotes the expression of class II flagellar genes [7]. The expression of the class III genes that include the flagellin genes $f l a A$, flaB, and $f l a C$ as well as several genes encoding chemotactic receptors are directly activated by the conserved transcriptional regulator CtrA [8]. The mechanism that turns on the expression of class III genes in S. meliloti is still unknown. In Caulobacter crescentus, the flagellar expression hierarchy has been thoroughly studied. In this case, CtrA activates the expression of the class II genes that encode the proteins of the MS ring and the flagellar export apparatus as well as the regulatory proteins RpoN and FlbD. Upon completion of the export apparatus and the MS-ring, FlbD is phosphorylated by an unknown kinase and together with the sigma factor RpoN promote transcription of class III/IV genes, whose products form the axial rod, the L- and P-rings, the hook and the flagellar filament $[9,10]$.

Rhodobacter sphaeroides is an $\alpha$-proteobacterium with two flagellar systems of different phylogenetic origin [11]. Under the growth conditions commonly used in the laboratory, the fla1 genes are expressed and direct the assembly of a single subpolar flagellum [12]. It has been shown that the fla1 genes of $R$. sphaeroides were acquired by horizontal transfer. In contrast, the gene products of the vertically inherited fla 2 genes enable, under particular conditions, the synthesis of several polar flagella $[11,13]$. The expression of the fla1 genes follows a hierarchical expression pattern in which the early genes are expressed under the control of RpoN1 and the activator proteins FleQ and FleT whereas the late genes are dependent on FliA [14]. In contrast, expression of the fla 2 genes is dependent on the two-component system (TCS) formed by the hybrid histidine kinase, CckA, the histidine phosphotransferase, ChpT, and the response regulator $\mathrm{CtrA}$
[15]. The signal that fully activates CckA as a kinase has not been elucidated yet in this bacterium; therefore, the Fla2 system has been studied in strains that carry two mutations: one that inactivates the master regulator of the Fla1 system, and the other, a constitutive mutation in CckA. These strains, in consequence, have a Fla $1^{-} / \mathrm{Fla}^{+}$ phenotype $[11,15,16]$.

The CckA/ChpT/CtrA TCS, is broadly distributed among $\alpha$-proteobacteria. In some bacterial species this system is essential given that CtrA regulates the expression of genes that control the cell cycle; in contrast in many other bacteria, CtrA is not essential. In general, genes controlled by CtrA are enriched in certain functional categories, i.e. cell motility, signal transduction, and cell wall/membrane envelope biogenesis [17].

In $C$. crescentus the architecture of the CtrA promoters has been recently analyzed at genomic level by means of a global 5' RACE protocol combined with a search for CtrA binding sites using a weight position matrix generated from ChIP experiments. From these studies it was observed that there are two classes of CtrA binding motifs, a full site represented by the sequence TTAA (N7) TTAA, and a half site (TTAA) [18]. Previously, a global analysis of the control regions of the CtrA-dependent genes, using MEME and BIOPROSPECTOR, also identified the sequence for the full site, the ungapped variant TTAA CCAT, and the short motif TTAA [19]. In addition, it was reported that the CtrA binding sites involved in transcriptional activation are located near the -35 promoter region. In contrast, in those promoters where CtrA acts as a repressor, the CtrA half binding motif overlaps with the 10 promoter region [18]. The relevance of the TTAA (N7) TTAA motif for transcriptional activation has been proved by site directed mutagenesis [20].

For other bacteria, it was suggested that CtrA could have similar recognition sites based on the fact that related motifs have been identified upstream of genes controlled by CtrA [17, 21-24]. Supporting this idea, it has been observed that ctrA from Rickettsia prowa$z e k i i$ is partially functional in C. crescentus, and that ctrA from C. crescentus is functional in Sinorhizobium meliloti $[25,26]$.

In many species, the flagellar genes presumably controlled by CtrA are expressed as divergent transcriptional units, and in many cases, the control region encompasses less than 100 bp [27-29].

In this work we analyzed two divergent promoter regions carrying the fla2 promoters flgB2p-fliI $2 p$ and $f l i F 2 p-f l i L 2 p$. The architecture of these regulatory regions was characterized using 5'-RACE, site directed mutagenesis and chromatin immunoprecipitation (ChIP) assay. From these analyses we conclude that CtrA directly activates the fla 2 promoters using more than a single architecture. 


\section{Methods}

Strains, plasmids and oligonucleotides

All plasmids and bacterial strains used in this work are listed in Table 1. The oligonucleotides used in this work are listed in Table 2.

\section{Media and growth conditions}

$R$. sphaeroides was grown in Sistrom's minimal medium [30]. When indicated the strains were grown in Sistrom minimal medium in which succinic acid was reduced to $80 \mu \mathrm{M}$ or replaced by $0.2 \%$ casamino acids. Heterotrophic growth was carried out at $30{ }^{\circ} \mathrm{C}$ in the dark with orbital shaking at $180 \mathrm{rpm}$. Photoheterotrophic growth on plates was achieved by incubation in a polycarbonate anaerobic jar containing a BD Gas Pack EZ anaerobe pouch system 8 (Becton, Dickinson and Company) and illuminated with two $75 \mathrm{~W}$ incandescent bulbs. Photoheterotrophic liquid cultures were grown in completely filled screw-cap tubes under continuous illumination. Escherichia coli was grown in LB medium [31] at $37{ }^{\circ} \mathrm{C}$. When required, antibiotics were used at the following concentrations: for $R$. sphaeroides, kanamycin $(25 \mu \mathrm{g} / \mathrm{ml})$, tetracycline $(1 \mu \mathrm{g} / \mathrm{ml})$, spectinomycin $(50 \mu \mathrm{g} / \mathrm{ml})$. For E. coli, kanamycin $(50 \mu \mathrm{g} / \mathrm{ml})$, tetracycline $(12 \mu \mathrm{g} / \mathrm{ml})$ ampicillin $(100 \mu \mathrm{g} / \mathrm{ml})$, spectinomycin
(50 $\mu \mathrm{g} / \mathrm{ml})$, chloramphenicol $(20 \mu \mathrm{g} / \mathrm{ml})$, gentamycin (30 $\mu \mathrm{g} / \mathrm{ml})$.

\section{Standard techniques of molecular biology}

Routine genetic manipulations were performed as described elsewhere [31]. Restriction and modification enzymes were purchased from Thermo Fisher Scientific. PrimeSTAR HS from Takara Bio Inc. was used for DNA amplification.

\section{Isolation of the AR1 mutant strain}

The intercistronic region between flgB2 and fliI2 as well as the $5^{\prime}$ region of each gene was replaced with the omega-Spc ${ }^{\mathrm{R}}$ cartridge. For this a chromosomal region of 2250 bp was amplified using the oligonucleotides DinterB2For and DinterI2Rev. The PCR product encompassing from the end of flgC2 to the end of fliI2, was cloned in pCR2.1-TOPO, digested with StuI and religated. The StuI digestion allowed the removal of two internal fragments, one of 392 and the other of $126 \mathrm{bp}$. The resulting linearized plasmid was self-joined to bring together the C-terminal half of flgB2 with the C-terminal half of fliI2. This plasmid was purified, digested with StuI and ligated with the omega-Spc ${ }^{\mathrm{R}}$ cartridge obtained from the pBOR plasmid. The complete fragment was then

Table 1 Strains and plasmids used in this work

\begin{tabular}{|c|c|c|}
\hline \multicolumn{3}{|l|}{ Strains } \\
\hline \multicolumn{3}{|l|}{ Rhodobacter sphaeroides } \\
\hline WS8N & wild-type; spontaneous $\mathrm{Nal}^{\mathrm{R}}$ & {$[52]$} \\
\hline AM1 & WS8N derivate, Fla2 ${ }^{+}, \Delta f l e Q:: k a n ~ c c k A_{L 391}$ & [16] \\
\hline EA1 & AM1 derivative, $\triangle c t r A:: a a d A$ & {$[15]$} \\
\hline AR1 & AM1 derivative $\Delta f l g B 2$-flil $2: \Omega^{\mathrm{Spc}}$ & This work \\
\hline \multicolumn{3}{|l|}{ Escherichia coli } \\
\hline TOP10 & Cloning strain & Invitrogen \\
\hline S17-1 & recA endA thi hsdR RP4-2-Tc::Mu::Tn7 & {$[53]$} \\
\hline Rosetta & Protein expression strain, $\mathrm{Cm}^{\mathrm{R}}$ & Novagen \\
\hline \multicolumn{3}{|l|}{ Plasmids } \\
\hline pTZ19R & Cloning vector $A p^{R}$ & Fermentas \\
\hline pCR2.1-TOPO & Cloning vector, $A p^{R}$ & Invitrogen \\
\hline pJQ200mp18 & Mobilizable suicide vector; $\mathrm{Gm}^{\mathrm{R}}$ & [32] \\
\hline pRK415 & Expression vector for $R$. sphaeroides & {$[54]$} \\
\hline pRK415/uidA & pRK415 carrying the uidA-aadA cassette & This work \\
\hline pWM5 & Vector source of the uidA-aadA cassette & {$[55]$} \\
\hline pRK_flgB2p::uidA-aadA & pRK415/uidA carrying flgB2p & This work \\
\hline pRK_flgE2p::uidA-aadA & pRK415/uidA carrying flgE2p & This work \\
\hline pRK_flif2p:.uidA-aadA & pRK415/uidA carrying fliF2p & This work \\
\hline pRK_flil2p::uidA-aadA & pRK415/uidA carrying flil2p & This work \\
\hline pRK_fliL2p:.:uidA-aadA & pRK415/uidA carrying fliL2p & This work \\
\hline
\end{tabular}


Table 2 Oligonucleotides used in this work ${ }^{a}$

\begin{tabular}{|c|c|}
\hline \multicolumn{2}{|c|}{ To obtain the strain AR1 } \\
\hline DinterB2for & TCTAGATGGAACTCCTITCAACGAC \\
\hline Dinterl2rev & TCTAGAACGGTCGTCGTCTACGA \\
\hline \multicolumn{2}{|c|}{ To obtain pBAD_ctrA } \\
\hline CtrABADFwSac & GAGCTCATGAGAATACTGCTGGTGGA \\
\hline CtrABADRvEco & GAATTCTCCAGCCCACCCTTCCCG \\
\hline \multicolumn{2}{|c|}{ To clone the wild-type promoters } \\
\hline \multicolumn{2}{|l|}{ flgB2p (336 bp) } \\
\hline FlgBI5 & GAGTCTGATATCCGGGCGTGTCGGCATTG \\
\hline $\mathrm{FlgB} \mid 2$ & GAATTCCACCCGGTCGCCCAGCGCGG \\
\hline \multicolumn{2}{|l|}{ flgE2p (303 bp) } \\
\hline pflgE2for & GAATTCCGGTGCGAAACAACAGACT \\
\hline pflgE2rev & GAGCTCATTGGCCGACTGCGTGAT \\
\hline \multicolumn{2}{|l|}{ flif2p (331 bp) } \\
\hline FliFL5 & GAGCTCAGACCGAGCACGGCCAGGAA \\
\hline FliFL2 & GAATTCAGGCCCGACCAGGTGGCGTAG \\
\hline \multicolumn{2}{|c|}{ flil $2 p$ (product of 336 bp) } \\
\hline FliBI3 & GAATTCGATATCCGGGCGTGTCGGCATTG \\
\hline FliBl6 & GAGCTCCACCCGGTCGCCCAGCGCGG \\
\hline \multicolumn{2}{|l|}{ fliL2p (331 bp) } \\
\hline FliFL3 & GAATTCAGACCGAGCACGGCCAGGAAC \\
\hline FliFL6 & GAGCTCAGGCCCGACCAGGTGGCGTAG \\
\hline
\end{tabular}

For the $5^{\prime}$ RACE experiments

$\begin{array}{ll}\text { flgB2 RACE } & \text { CGCACCATCTCATCCTCGAGCGAG } \\ \text { N3' flgB2 RACE } & \text { GACCGTGTTGCCGTGGGCGAAG } \\ \text { flgE2 RACE } & \text { GATATCCAGGGCGCTCGCGGTCGAGA } \\ \text { N3' flgE2 RACE } & \text { CATTCCTCCACCCGCCGTATGGTGT } \\ \text { flif2 RACE } & \text { CACCTCGTAGGCCGCGCCCTGCGCC } \\ \text { flil2 RACE } & \text { GGGCAGGATCGCCACCTCGTGCGACGAA } \\ \text { N3' flil2 RACE } & \text { GCCGCAGAACCTCGCCGCCGAGGATG } \\ \text { fliL2 RACE } & \text { CCAAGGCTGATCACGATCGGGTCGA } \\ \text { N3' fliL2 RACE } & \text { CGATCGGCACGAAGGCGATGTCGGGA }\end{array}$

For site directed mutagenesis

\begin{tabular}{|c|c|}
\hline$f l g B 2 p-10$ & GTTCACCAAGGCGCAAGGGCGATTCCTTAG \\
\hline flgB2p $-13 /-14$ & CACCAAGGCTTCGGGGCGATTC \\
\hline flgB2p $-17 /-18$ & CAAGGCTTAAGGCGGATTCCTITAGAAAG \\
\hline $\mathrm{flgB} 2 \mathrm{p}-23 /-24$ & CTTAAGGGCGATTGGTTAGAAAGGGTAAG \\
\hline$f l g B 2 p-27 /-28$ & GGGCGATTCCTTCGGAAAGGGTAAGGCGC \\
\hline$f \lg B 2 p-35$ & TAGAAAGGGTGGGGCGCGAAC \\
\hline$f l g B 2 p-42 /-43$ & GAAAGGGTAAGGCGGCAACAAAGAGGGATTG \\
\hline flif2p -10 & CCACATCCGTCCCGGATGGTCGGGC \\
\hline flif2p -35 & GATTGTTGGGCCACATCCGTCA \\
\hline flil $2 p-10$ & TTGTTCGCGCCTCCCCCCTTCT \\
\hline flil $2 p-26 /-27$ & TTAAGGGCGAGG \\
\hline flil $2 p-35$ & CACCAAGGCTTCGGGGCGATTC \\
\hline
\end{tabular}

Table 2 Oligonucleotides used in this work ${ }^{\mathrm{a}}$ (Continued)

\begin{tabular}{ll}
\hline flil2 $p-47 /-48$ & CTCCCTCGATCGGTGCCACCAAGGCTTAAGGGC \\
fliL2p -10 & GTCGATCTAGGGGCCGGATCCC \\
fliL2p -35 & GATTGTTGGGCACATCCGTCA \\
\hline
\end{tabular}

${ }^{a}$ The undelines bases correspond to the changes introduced in the wild type sequence

subcloned into pJQ200mp18 [32]. This plasmid was introduced to $E$. coli $\mathrm{S} 17-1$ and subsequently transferred to $R$. sphaeroides by conjugation [33]. Since pJQ200mp18 cannot replicate in $R$. sphaeroides, the double-recombination event was selected on LB agar plates in the presence of spectinomycin and $5 \%$ sucrose. The mutant was verified by PCR.

Fusion of the flagellar promoters to the reporter gene uidA The regulatory region of the fla 2 promoters for the genes flgB2, fliI2, fliF2, fliL2 and flgE2 was amplified by PCR using the oligonucleotides indicated in Table 2. The product was gel purified and cloned in pTZ19R for sequencing. Subsequently, each fragment was subcloned in pRK415/uidA. This plasmid enables to create a transcriptional fusion with the uidA gene that encodes for the $\beta$-glucuronidase. In pRK415/uidA, the uidA-aadA cassette was cloned in the BamHI site, the orientation of the fragment was selected in such a manner that the uidA gene can be transcribed from a promoter cloned as an EcoRI-SstI fragment.

\section{$\beta$-Glucuronidase assay}

Cell-free extracts from exponential phase cultures grown photoheterotrophically were tested for $\beta$-glucuronidase activity following the previously reported protocol $[34,35]$. As standard, a curve of different concentrations of 4-methyl-umbelliferone (Sigma-Aldrich) was used. Specific activities are expressed as $\mu \mathrm{mol} / \mathrm{min} /$ $\mathrm{mg}$ of 4-methyl-umblliferone formed. Protein content was determined with a Bio-Rad protein assay kit, using bovine serum albumin as standard.

\section{Site directed mutagenesis}

Mutagenesis was performed essentially following the method of Kunkel [36] with an uracil-containing singlestranded DNA as template and the appropriate oligonucleotides (Table 2). pTZ19R plasmids carrying flgB2p, $f l i I 2 p$, fliL $2 p$, and fliI2 $p$ were used as templates. The presence of the mutation was verified by sequencing.

\section{5'-rapid amplification of CDNA ends (5'-RACE) analysis}

Bacterial cells from cultures grown to mid-log phase in $0.2 \%$ casamino acids, were collected at $4{ }^{\circ} \mathrm{C}$ and immediately used to extract the complete pool of RNA using the RiboPure-Bacteria kit (ThermoFisher Scientific) according 
to the manufacturer's instructions. Residual DNA in the samples was removed using DNaseI (Roche). To determine the $5^{\prime}$ end of the mRNA transcripts of flgB2, fliI2, fliF2, fliL2, and flgE2, the primers shown in Table 2 were used. The PCR products obtained from these reactions were cloned in pCR2.1-TOPO and sequenced.

\section{His6X-CtrA purification and antibody production}

ctrA was amplified using the oligonucleotides ctrABADFwSac and ctrABADRvEco. The amplification product was cloned into $\mathrm{pBAD} / \mathrm{HisA}$ (Invitrogen). This construction was introduced into Rosetta and a culture of this strain grown at mid-log phase was induced with $0.2 \%$ L-arabinose for $4 \mathrm{~h}$ at $37^{\circ} \mathrm{C}$. Cells were collected by centrifugation and resuspended in $1 / 100$ of the original volume in phosphate buffered saline (PBS) $0.058 \quad \mathrm{M} \quad \mathrm{Na}_{2} \mathrm{HPO}_{4}, \quad 0.017 \quad \mathrm{M}$ $\mathrm{NaH}_{2} \mathrm{PO}_{4}, 0.068 \mathrm{M} \mathrm{NaCl}, \mathrm{pH}$ 7.4. The cell suspension was sonicated in an ice bath for five bursts of $10 \mathrm{~s}$. Cell debris were removed by centrifugation and the supernatant was mixed with Ni-NTA-agarose beads (Quiagen) and incubated for $1 \mathrm{~h}$ on ice in the presence of $20 \mathrm{mM}$ imidazole. The beads were loaded into a polypropylene column $(1 \mathrm{ml}$ of capacity) and washed with $\mathrm{PBS} / 30 \mathrm{mM}$ imidazole/ $200 \mathrm{mM} \mathrm{NaCl}$. The protein was eluted using PBS containing $250 \mathrm{mM}$ imidazole.

Six three weeks old BALB/C female mice, were immunized intraperitoneally with $20 \mu \mathrm{g}$ of His6X-CtrA protein (for each mice) in incomplete Freund's adjuvant, and 3 weeks later reimmunized. Two weeks later the mice were bled and antisera were obtained by low-speed centrifugation. The specificity of the anti-CtrA antibodies was tested by immunoblotting following standard protocols [37]; in this experiment, total cell extracts from AM1 and EA1 strains were used respectively as positive and negative controls.

\section{Chromatin immunoprecipitation (ChIP)}

ChIP was carried out according to the protocol previously reported [33] with minor modifications as follows: $15 \mathrm{ml}$ of a photoheterotrophic culture of $R$. sphaeroides, grown in Sistrom's medium with $0.2 \%$ casamino acids, were transferred to a $125 \mathrm{ml}$ Erlenmeyer flask when the $\mathrm{OD}_{600}$ reached 0.5. Immediately, $0.41 \mathrm{ml}$ of $37 \%$ of freshly prepared formaldehyde was added and incubated for $10 \mathrm{~min}$ at $30{ }^{\circ} \mathrm{C}$ with slow shaking. After this time, the flasks were incubated on ice for $30 \mathrm{~min}$. The cells were washed three times with PBS buffer and then resuspended in $250 \mu \mathrm{l}$ of PBS with protease inhibitors (complete, EDTA-free protease inhibitor cocktail tablets from Roche). The sample was incubated at room temperature with lysozyme $(80 \mu \mathrm{g} /$ $\mathrm{ml}$ ) for $15 \mathrm{~min}$; after this time, $2.5 \mu \mathrm{l}$ of Triton X-100 and $5 \mu \mathrm{l}$ of EDTA $50 \mathrm{mM}$ were added, and carefully mixed. After $10 \mathrm{~min}$, the sample was sonicated 10 times for $8 \mathrm{~s}$ (30\% duty cycle) on ice. Cell debris were removed by centrifugation at $10,000 \times g$ for $5 \mathrm{~min}$. The supernatant was transferred to a clean tube containing $100 \mu \mathrm{l}$ of a mixture of Protein A Sepharose/DNA/BSA $(100 \mu \mathrm{g}$ of sonified herring sperm DNA/100 $\mu \mathrm{g}$ of BSA). The sample was incubated at $4{ }^{\circ} \mathrm{C}$ on a rocking platform shaker, for $2 \mathrm{~h}$, and centrifuged for $3 \mathrm{~min}$ at $550 \times g$. The supernatant was transferred to a clean tube, and an aliquot of $20 \mu \mathrm{l}$ was withdrawn and labeled as input. The remaining sample was mixed with $4 \mu \mathrm{l}$ of anti-CtrA antibody and incubated overnight at $4{ }^{\circ} \mathrm{C}$ on a rocking platform shaker. The complexes were captured by adding $100 \mu \mathrm{l}$ of Protein A-Sepharose/DNA/BSA and continuing incubation for $2 \mathrm{~h}$. The immunoprecipitated material was washed twice in low, and high salt buffers (Low: $0.1 \%$ SDS, $1 \%$ Triton X-100, 2 mM EDTA, $150 \mathrm{mM} \mathrm{NaCl}$, $20 \mathrm{mM}$ Tris $\mathrm{pH}$ 8. High: $0.1 \%$ SDS, $1 \%$ Triton $\mathrm{X}-100$, $2 \mathrm{mM}$ EDTA, $500 \mathrm{mM} \mathrm{NaCl}, 20 \mathrm{mM}$ Tris $\mathrm{pH}$ 8), twice in $\mathrm{LiCl}$ buffer $(0.25 \mathrm{M} \mathrm{LiCl}, 1 \%$ Triton X-100, 1\% deoxycholate, $1 \mathrm{mM}$ EDTA, $10 \mathrm{mM}$ Tris $\mathrm{pH}$ 8) and twice in TE buffer (10 mM Tris pH 8, 1 mM EDTA). The sample was resuspended in $500 \mu \mathrm{l}$ of elution buffer $(1 \%$ SDS, $0.1 \mathrm{M} \mathrm{NaHCO} 3,300 \mathrm{mM} \mathrm{NaCl}$ ) and incubated overnight at $65{ }^{\circ} \mathrm{C}$ to reverse the cross-linking. Input samples were also incubated overnight at $65{ }^{\circ} \mathrm{C}$ in elution buffer. The samples were treated for $30 \mathrm{~min}$ with $50 \mu \mathrm{g}$ of RNase for $30 \mathrm{~min}$ at $37^{\circ} \mathrm{C}$, and subsequently with $120 \mu \mathrm{g}$ of proteinase $\mathrm{K}$ for $30 \mathrm{~min}$. DNA was purified using the QIAquick PCR purification kit. The procedure was carried out three times for AR1 and EA1 strains carrying the plasmid pRK flgB2p::uidA-aadA; and twice for AR1 carrying pRK flgB2p - 10::uidA-aadA or pRK_flgB2p - 35::uidA-aadA.

\section{Semiquantitative PCR}

To assess the presence of the flgB2-fliI2 region in the ChIP samples, we carried out a PCR reaction and evaluated the amount of product at different cycles of the reaction. The DNA products were analyzed by acrylamide gel electrophoresis and quantified using Image J software [38]. The data represent the average of three independent experiments.

\section{Identification of the CtrA binding sites}

The DNA sequence containing the fla2 genes was analyzed using a position weight matrix (PWM) built from the regulatory region of 54 genes identified to be controlled by CtrA in C. crescentus [6] with the tool matrix-scan included in the Regulatory Sequence Analysis Tools (RSAT) (http:// embnet.ccg.unam.mx/rsat). Sequence alignments were carried out using MUSCLE [39]. 


\section{Results}

\section{Construction of reporter plasmids containing selected} fla2 promoters

The R. sphaeroides WS8N genome consists of two chromosomes and two plasmids. Most of the fla 2 genes are clustered in a region of approximately $32.3 \mathrm{~Kb}$ localized in chromosome I (Fig. 1) and the gene encoding flagellin of the Fla2 flagellum is in plasmid A $[11,40]$.

The fla 2 chromosomal region was analyzed searching for putative CtrA binding sites as described in Materials and Methods. Using a threshold of 5, the search identified 57 hits, many of which were within coding regions. A threshold of 5.5 identified 34 hits, and the best hits included the regulatory regions of $\operatorname{mot} B 2$, $f l g E 2, \operatorname{mot} A 2$, as well as the intercistronic regions containing the divergent promoters of fliF2-fliL2, flgB2-fliI2 and flgJ2-fliK2 (Additional file 1). Given the palindromic nature of the CtrA binding site, frequently two hits were computed for each promoter; we also noted that in a single regulatory region several hits were occasionally found (for instance upstream of motA2). Eleven hits mapped within coding regions, suggesting a high rate of false negatives.

To evaluate the functional relevance of some of the identified sites, we cloned the intercistronic regions located between fliL2-fliF2, and flgB2-fliI2 in a plasmid that carries the reporter gene uidA (pRK415/uidA), in order to create a transcriptional fusion between these promoters and the uidA gene, which encodes for the enzyme $\beta$-glucuronidase. To test the activity of the promoters fliL $2 p$, fliF $2 p$, flgB $2 p$ and fliI $2 p$, these regions were cloned in both orientations regarding uidA. These constructions were introduced to the AM1 mutant strain (for simplicity this strain will be named as wild type from now on) and its $\triangle c t r A$ derivative (EA1 strain). The amount of $\beta$-glucuronidase produced by each strain was determined.

It was observed that all these plasmids promoted an elevated synthesis of $\beta$-glucuronidase in the AM1 (WT) strain, but not in the EA1 $(\Delta c t r A)$ strain (Table 3$)$. This suggests that each one of these regions contain a functional CtrA-dependent promoter. The region upstream of flgE2 was also cloned into pRK415/uidA, in order to test a region that does not contain a divergent promoter. $\beta$-glucuronidase activity promoted by flgE $2 p$ was also dependent on the presence of CtrA (Table 3).

To validate our plasmid system, we cloned the fliQ promoter from $C$. crescentus, previously known to be activated by CtrA, into pRK415/uidA and it was introduced to the wild-type (AM1) and EA1 strains. A high level of $\beta$-glucuronidase was detected in AM1 but not in EA1 (data not shown).

\section{Determination of the transcriptional start site of fliL2p, fliF $2 p$, flgB2 $p$, flil $2 p$ and flgE2 $p$}

To further characterize fliL $2 p, f l i F 2 p, f l g B 2 p, f l i I 2 p$ and $f l g E 2 p$, we proceeded to determine the transcriptional start site (TSS) by 5'-RACE. The TSS was established by sequencing five independent clones from each sample. For these promoters, the initiation nucleotide was always

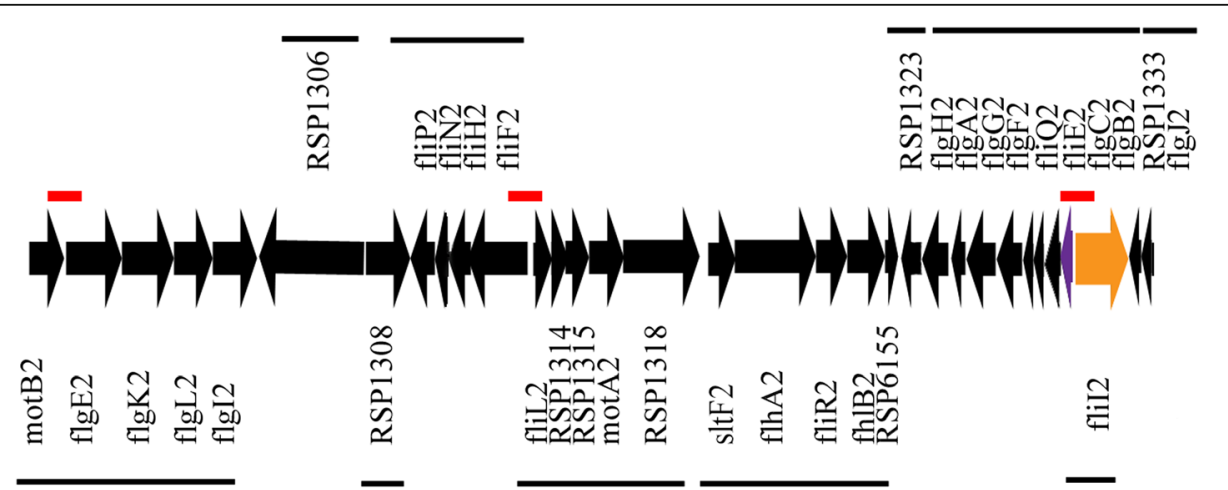

Fig. 1 Cluster and operon arrangement of the fla2 genes between motB2 and flil2. Arrows indicate the direction of transcription. The name of the genes that are transcribed from left to right are indicated under the arrows, and the genes transcribed in the opposite direction are indicated above the arrows. The red lines indicate the regulatory regions analyzed in this work. For an easy identification, the arrows representing flgB2 and flil2 are colored in violet and orange, respectively. In the cluster, motB2 encodes the motor protein B; flgE2, the hook protein; flgK2 and flgL2, the hook associated proteins 1 and 3, respectively; flg/2, the P-ring protein; RSP_1316 a putative histidine kinase; RSP_1318 a putative response regulator; fliP2 membrane component of the secretion apparatus; fliN2, a switch complex/secretion protein; fliH2, a soluble component of the secretion system; fliF2, the MS-ring protein; fliL2, a motor control protein; RSP_1414, RSP_1315, conserved hypothetical proteins; motA2, the stator protein A; RSP_1318, a conserved hypothetical protein; SltF, the flagellar soluble lytic transglycosylase (named before flgJB2); flhA2, fliR2, flhB2, membrane components of the secretion apparatus; RSP_6155, conserved hypothetical protein; RSP_1323 similar to FliL; flgH2, L-ring protein; flgA2, chaperone for P-ring formation; flgG2, distal rod protein; flgF2, rod protein; fliQ, membrane component of the secretion apparatus; fliE, periplasmic protein related with the secretion apparatus; flgC2, flgB2, proximal rod proteins; flil2 cytoplasmic component of the secretion system, ATPase component; RSP_1333 putative secretion chaperone; flgJ2, cap rod protein 
Table $3 \beta$-glucuronidase activity promoted by the regulatory regions of flgE2p, fliF2p, flgB2p, fliL $2 p$, and flil $2 p^{a}$

\begin{tabular}{lll}
\hline & WT & $\Delta c t r A$ \\
\hline flgE2p & $148 \pm 32$ & $1.4 \pm 0.36$ \\
fliF2p & $166 \pm 27$ & $1.0 \pm 0.24$ \\
flgB2p & $125 \pm 24$ & $0.52 \pm 0.12$ \\
flgL2p & $204 \pm 36$ & $0.28 \pm 0.06$ \\
flil2p & $99 \pm 19$ & $0.37 \pm 0.09$ \\
\hline
\end{tabular}

${ }^{\text {a }}$ The plasmids $p R K 415 /$ uidA carrying the indicated regulatory regions were introduced to AM1 (WT) and EA1 ( $\triangle \mathrm{ctrA})$ and the amount of $\beta$-glucuronidase was determined. Activity is expressed as $\mu \mathrm{mol}$ of 4 -methyl-umblliferone/min/ $\mathrm{mg}$ of protein. The values represent an average of three independent experiments

a purine (Fig. 2). The regions upstream of the TSS were aligned using MUSCLE and also by visual inspection; from this alignment it was possible to detect a sequence similar to the CtrA-binding site (yellow shaded in Fig. 2). The distance between the TSS and the final boundary of the putative CtrA-binding site is 23 or $24 \mathrm{nt}$, which is in agreement with the findings made in $C$. crescentus. In this bacterium it was observed that the CtrA-binding site is located near the -35 promoter region in CtrA-activated promoters [18, 20]. It should be stressed that the putative CtrA-binding sites identified from this sequence alignment, concur with those identified bioinformatically using a threshold of 5.5, except for the divergent promoters flgB2p and fliI $2 p$.

From the alignment (Fig. 2), we also observed an invariant $A$ at the -11 position, a $G$ at -4 and, a variable distance between the TSS and the start codon, ranging from 33 to $12 \mathrm{bp}$. Under the idea that the -11 position could be a part of the -10 promoter region, we presume that the identity of the -11 position could be important for transcription.

As can be observed in Fig. 2, a gap was introduced between the left and right conserved elements of the CtrA-binding site for flgB2 $p$ and fliI $2 p$. Therefore, these sites do not conform to the consensus CtrA-binding site, and in consequence they were not found by the algorithm in the initial analysis. For $f \lg B 2 p$, the algorithm predicted two different sites. The first has a score of 8.3 and overlaps the TSS. The other starts one nucleotide upstream of the highlighted sequence in Fig. 2 but has several differences from the consensus and a score just above the threshold (5.9), which contrasts with the high score observed for the predicted sites upstream of $f l i F 2 p$, fliL $2 p$ or $f l g E 2 p$ (i.e., 9.7, 9.3 and 10.3, respectively). For fliI $2 p$, the algorithm predicted one CtrA-binding site (score 7.1), which starts upstream of the sequence shown in Fig. 2, and overlaps with the highlighted sequence in Fig. 2, in such a manner that the right element of this site is the left element highlighted in Fig. 2. To clarify the relevance of these putative CtrA binding sites, additional experiments were carried out.

\section{Site directed mutagenesis of the fla2 promoters}

To gain insight on the role of the sequences identified from the alignments of flgB $2 p$, fliI $2 p, f l i F 2 p$ and $f l i L 2 p$ such as the putative CtrA binding site or the putative 10 promoter region, we proceeded to mutagenize the nucleotides shown in Fig. 3a. For each promoter we changed two bases of the proposed CtrA-binding site and two bases of the putative -10 promoter region.

The promoter regions carrying these changes were cloned in pRK415/uidA and introduced to AM1. The amount of $\beta$-glucuronidase present in total cell extracts was determined. We noticed a strong reduction in the enzymatic activity when these changes were introduced (Fig. 3a), suggesting that these regions could indeed represent the functional CtrA binding site and the -10 promoter region. To support this notion, we decided to further analyze $f \lg B 2 p$ introducing additional changes along the regulatory region (Fig. $3 \mathrm{~b}$ ). The plasmids carrying these changes were introduced to AM1 and the amount of $\beta$-glucuronidase was determined. We noticed a reduction in the amount of $\beta$-glucuronidase when the positions immediately upstream of the -11 position (13/-14), and the right element of the CtrA-binding site $(-27 /-28)$ were changed (Fig. 3b). Mutations at positions $-17 /-18,-23 /-24$, and $-42 /-43$ did not severely affect the expression of the reporter gene. These results

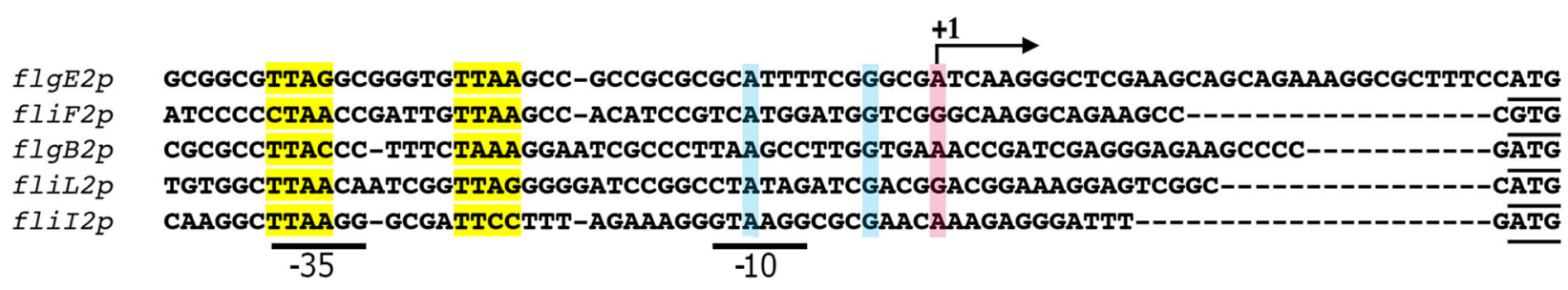

Fig. 2 Transcriptional start sites of the flgE2, flif2, flgB2, fliL2 and flil2 promoters The transcriptional start site (+ 1), is indicated by a bent arrow and the nucleotide is shaded in pink. The conserved nucleotides A and $\mathrm{G}$ at -11 and -4 positions, respectively are shaded in blue. The nucleotides matching with the consensus CtrA-binding site are highlighted in yellow. The translation codons for FlgE2, FliF2, FlgB2, FliL2 and Flil2, are underlined 


\begin{tabular}{|c|c|c|}
\hline \multicolumn{3}{|l|}{ A } \\
\hline fliF2p WT & TCCCCCTAACCGATTGTTAAGCCACATCCGTCATGGATGGTCGGGCAAGGCAGAAGCCCGTG & 100 \\
\hline$f l i F 2 p-10$ & TCCCCCTAACCGATTGTTAAGCCACATCCGTCCCGGATGGTCGGGCAAGGCAGAAGCCCGTG & $<1$ \\
\hline$f l i F 2 p-35$ & TCCCCCTAACCGATTGTTGGGCCACATCCGTCATGGATGGTCGGGCAAGGCAGAAGCCCGTG & 2 \\
\hline$f l g B 2 p$ WT & CGCGCCTTACCCTITCTAAAGGAATCGCCCTPAAGCCTIGGTGAAACCGATCGAGGGAGAAGCCCCGATG & 100 \\
\hline$f l g B 2 p-10$ & CGCGCCTTACCCTTTCTAAAGGAATCGCCCTTGCGCCTTGGTGAAACCGATCGAGGGAGAAGCCCCGATG & 1 \\
\hline \multirow[t]{2}{*}{$f \perp g B 2 p-35$} & CGCGCCCCACCCTTTCTAAAGGAATCGCCCTTAAGCCTTGGTGAAACCGATCGAGGGAGAAGCCCCGATG & 3 \\
\hline & TGTGGCTTAACAATCGGTTAGGGGGATCCGGCCTATAGATCGACGGACGGAAAGGAGTCGGCCATG & 100 \\
\hline$f l i L 2 p-10$ & TGTGGCTTAACAATCGGTTAGGGGGATCCGGCCCCTAGATCGACGGACGGAAAGGAGTCGGCCATG & $<1$ \\
\hline$f l i L 2 p-35$ & TGTGGCCCAACAATCGGTTAGGGGGATCCGGCCTATAGATCGACGGACGGAAAGGAGTCGGCCATG & $<1$ \\
\hline fliI2p WT & CAAGGCTTAAGGGCGATTCCTITAGAAAGGGTAAGGCGCGAACAAAGAGGGATTTGATG & 100 \\
\hline$f l i I 2 p-10$ & CAAGGCTTAAGGGCGATTCCTTTAGAAAGGGGGAGGCGCGAACAAAGAGGGATTTGATG & $<1$ \\
\hline$f l i I 2 p-35$ & CAAGGCTTCGGGGCGATTCCTITAGAAAGGGTAAGGCGCGAACAAAGAGGGATTTGATG & 5 \\
\hline \multicolumn{3}{|l|}{ B } \\
\hline flgB2p WT & TTGTTCGCGCCTTACCCTTTCTAAAGGAATCGCCCTTAAGCCTTGGTGAAACCGATCGAGGGAGAAGCCCCGATG & 100 \\
\hline$f \operatorname{lgB} 2 p-42 /-43$ & TTGTTGCCGCCTTACCCTTTCTAAAGGAATCGCCCTTAAGCCTTGGTGAAACCGATCGAGGGAGAAGCCCCGATG & 87 \\
\hline$f l g B 2 p-27 /-28$ & TTGTTCGCGCCTTACCCTTTCCGAAGGAATCGCCCTTAAGCCTTGGTGAAACCGATCGAGGGAGAAGCCCCGATG & \\
\hline$f l g B 2 p-23 /-24$ & TTGTTCGCGCCTTACCCTTTCTAAACCAATCGCCCTTAAGCCTTGGTGAAACCGATCGAGGGAGAAGCCCCGATG & 92 \\
\hline$f \operatorname{lgB} 2 p-17 /-18$ & TTGTTCGCGCCTTACCCTITCTAAAGGAATCCGCCTTAAGCCTTGGTGAAACCGATCGAGGGAGAAGCCCCGATG & 73 \\
\hline$f 1 g B 2 p-13 /-14$ & TTGTTCGCGCCTTACCCTTTCTAAAGGAATCGCCCCGAAGCCTTGGTGAAACCGATCGAGGGAGAAGCCCCGATG & is \\
\hline fliI2p WT & CAAGGCTTAAGGGCGATTCCTTTAGAAAGGGTAAGGCGCGAACAAAGAGGGATTTGATG & 100 \\
\hline fliI2p $-26 /-27$ & CAAGGCTTAAGGGCGACCGGTTTAGAAAGGGTAAGGCGCGAACAAAGAGGGATTTGATG & \\
\hline \multicolumn{3}{|c|}{$\begin{array}{l}\text { Fig. } 3 \text { Activity of the wild-type and mutant versions of fiif2p, flgB2p, filiL2p and flil2p in the AM1 strain. The amount of } \beta \text {-glucuronidase shown } \\
\text { at the right, is expressed as percentage of the activity determined for the wild-type promoter. The values are the average of three independent } \\
\text { experiments, SD was less than } 25 \% \text {. The nucleotides shaded in red represent the mutated bases regarding the wild-type promoter. The } \\
\text { transcriptional start sites, are indicated by a bent arrow and the nucleotide is shaded in pink. The conserved A at - } 11 \text { is shaded in blue. The } \\
\text { nucleotides matching with the consensus CtrA-binding site are highlighted in yellow. The translational codon is underlined. a) Activity of the } \\
\text { wild-type and mutant promoters with changes affecting the A-11 and the CtrA-binding site. b) Activity of the wild-type and mutant promoters } \\
\text { affecting different regions in flgB2p and flilizp. The underlined nucleotides upstream the transcriptional start site, indicate the mutagenized } \\
\text { positions in the constructions tested in panel (a) }\end{array}$} \\
\hline
\end{tabular}

support the notion that specific positions at this promoter region are indeed relevant to achieve transcription whereas others do not make a significant contribution. Therefore, the region around the -11 position and the proposed CtrA binding site, including the left and right elements, are key for the expression of $f l g B 2 p$.

For fliI2p, the right element of the proposed CtrA binding site, was also mutagenized, and this change strongly reduced the amount of $\beta$-glucuronidase as compared with the wild type promoter (Fig. 3b), indicating that the proposed sequence could represent the actual CtrA-binding site. As mentioned in the previous section, a different site was predicted bioinformatically for this promoter. The right element of this putative site is in fact the left element highlighted in the alignment shown in Figs. 2 and 3. To obtain evidence of the contribution of this putative site, we mutagenized the $-47 /-48$ positions of fliI2p, which must represent the left element, but did not detect a reduction in the amount of $\beta$-glucuronidase when this mutant promoter was tested in pRK415/uidA (data not shown). These results lead us to the conclusion that the functional site for CtrA binding must be the sequences highlighted in yellow in Fig. 2.

As mentioned before, $f \operatorname{lgB} 2$ and $f l i 2$ are transcribed from divergent promoters as well as fliF2 and fliL2; 
nonetheless, from the above results we realized that the architecture of these promoter regions is different. Figure 4 illustrates how a single CtrA binding site is sufficient for activation of $f l g F 2 p$ and $f l i L 2 p$, whereas $f l g B 2 p$ and fliI $2 p$ are activated from independent CtrA binding sites.

\section{Binding of CtrA to flgB2p and flil $2 p$ promoters}

Attempts to detect binding of His6X-CtrA to different fla2 promoters by gel electrophoresis mobility shift assay (EMSA) and DNAse I footprinting were unsuccessful; therefore, we decided to undertake an in vivo approach using chromatin immunoprecipitation (ChIP) in order to reveal the binding of CtrA to the fla 2 promoters. For these experiments we used the plasmid pRK415/uidA carrying $f l g B 2 p$ in the AR1 strain, in which the chromosomal region corresponding to $f \operatorname{lgB} 2 p$ and $f l i L 2 p$ was deleted.

The amount of $f l g B 2 p$ immunoprecipited by $\alpha-C \operatorname{tr} A$ antibodies was detected by semi-quantitative PCR. A strong increase of the PCR product was observed in the sample obtained from AR1 as compared with that obtained from EA1 $(\triangle c t r A)$, indicating that CtrA binds to this region (Fig. 5a).

We also analyzed the amount of $f l g B 2 p$ precipitated by $\alpha$-CtrA antibodies using the AR1 strain transformed with the plasmids carrying $f \lg B 2 p-10$ and $f \lg B 2 p-35$ (constructions shown in Fig. 3a). Given the architecture of $f l g B 2 p$ and $f l i I 2 p$ it should be stressed that the change at the -10 region of $f l g B 2 p$ affects the CtrA-binding site of fliI $2 p$ (Fig. 4), so a reduction in the amount of product can be expected. From these experiments we observed a perceptible reduction in the amount of DNA that was immunoprecipitated by $\alpha$-CtrA antibodies when the putative CtrA-binding sites were mutagenized, supporting the idea that these sites are involved in the binding of CtrA (Fig. 5b).

\section{Analysis of the intercistronic region flgB-flil in other a- proteobacteria}

The flgB2 and fliI2 genes are syntenic in several $\boldsymbol{\alpha}$-proteobacteria. We analyzed the intercistronic region between these genes for seven species of Rhodobacteraceae and one from the Hyphomonadaceae family, order Rhodobacterales. These regulatory regions are shown in Fig. 6, and it is evident that there is a limited space for the promoters and the CtrA-binding sites. For Rhodobacter capsulatus, Dinoreoseobacter shibae and Ruegeria pomeroyi, it has been established that the expression of the flagellar genes is dependent on CtrA [29, 41, 42] and given that in the other species it is possible to find the presence of the gene encoding the histidine kinase $c c k A$, the phosphotransferase $\operatorname{chpT}$ along with $\operatorname{ctr} A$, an educated guess allows us to presume that in these bacteria the flagellar genes are also controlled by CtrA. Using the PWM previously published for C. crescentus [17], we searched for the CtrA-binding sites in these sequences using a threshold of 3 . From this analysis we noticed

\section{CTCCGACACGGGCTTCTGCCTTGCCCGACCATCCATGACGGATGTGGCTTAACAATCGGT GAGGCTGTGCCCGAAGACGGAACGGGCTGGTAGGTACTGCCTACACCGAATTGTTAGCCA $\longleftarrow$ FliF2 \\ TAGGGGGATCCGGCCTATAGATCGACGGACGGAACGGAGTCGGCCATGGCGGATGCG ATCCCCCTAGGCCGGATATCTAGCTGCCTGCCTTGCCTCAGCCGGTACCGCCTACGC}

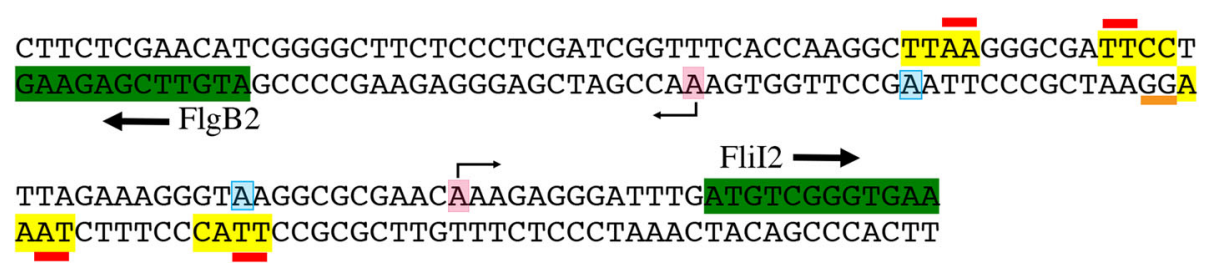

Fig. 4 Architecture of the divergent promoters flif2p-flil2p and flgB2p-flilp. The complete intercistronic region between these genes is shown. The coding region for FliF2, FliL2, FlgB2 and Flil2, represented by the initiation and 3 or 4 additional codons, is highlighted in green. The nucleotides matching the consensus CtrA-binding site are highlighted in yellow. For the intercistronic region between fliF2 and fliL2, the CtrA binding site is the same for both promoters; therefore, the highlighted nucleotides are on both strands. For the intercistronic region between $f l g B 2$ and flil2, the CtrA binding site for flil2p is highlighted on the top strand and the CtrA binding site for flgB2p is highlighted on the bottom strand. For reference the conserved $A$ at the -11 position is shaded in blue (on the top strand for flil2p and on the bottom strand for flgB2p). The transcriptional start site is indicated by a bent arrow and shaded in pink. For the flgB2-flil2 intercistronic region, a red bar below the sequence indicates the changes that the reduced the expression of flgB2p. A red bar above the sequence indicates the changes that reduced the expression of flil2p. The orange bar below the sequence indicates the mutagenized position that did not affect the expression of flgB2p $(-23 /-24)$ but is located in the CtrAbinding site for flil2p (highlighted in yellow in the top strand) 

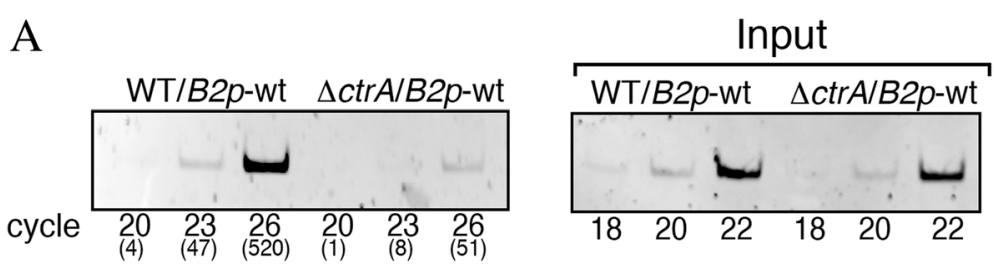

B
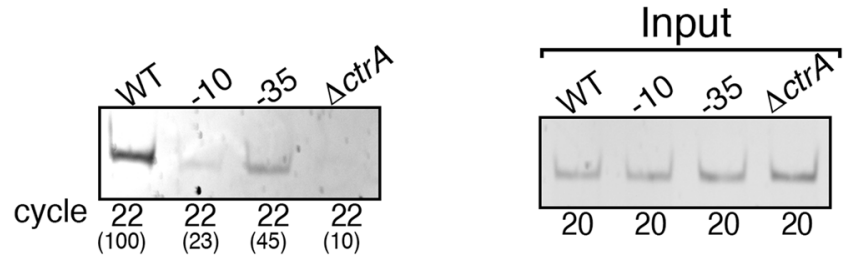

Fig. 5 Binding of CtrA to the flgB2-flil2 regulatory region. DNA material immunoprecipitated with a-CtrA antibodies, was amplified using the flgBl2 and flgBl5 oligonucleotides. Samples were taken at different cycles and analyzed by agarose gel electrophoresis. Panel $\mathbf{a}$ and $\mathbf{b}$ show one representative experiment out of three independent assays. a) Samples of AM1 (WT) and EA1 (4ctrA) carrying pRK_flgB2p::uidA-aadA (B2p-wt) were amplified during the number of cycles indicated below. The numbers in parenthesis represent the value obtained from the densitometric analysis. Input, shows the amplification products from an aliquot taken from each sample before ChIP (total chromatin input DNA). b) Samples of AR1 carrying pRK_flgB2p::uidA-aadA (WT) or the mutant versions pRK_flgB2p-10::uidA-aadA (- 10) and pRK_flgB2p - 35::uidA-aadA (- 35), and EA1 carrying pRK_flgB2p::uidA-aadA $(\Delta c t r A)$. The values in parenthesis represent the percentage of product relative to the amount detected for the wild type. Input shows the amplification products from an aliquot taken from each sample before ChIP

that for some species it was not possible to find putative CtrA binding sites with scores above 3.5 , and in other cases only one site with a high score was found (Fig. 6). From this, it seems possible that a single CtrA binding site could be used to activate these promoters in Dinoroseobacter shibae and Jannaschia sp, whereas two CtrA-binding sites seem to be required for activation in Ketogulonigenium vulgarum. Nonetheless, from this analysis it emerges that more than one type of architecture is possible.

\section{Discussion}

We have previously shown that in $R$. sphaeroides the expression of the fla2 genes is controlled by CtrA [15]. In this work we present evidence indicating that CtrA binding directly activates transcription of these genes. From our results we inferred that the binding site for this transcription factor should be similar to the one already reported for $C$. crescentus, given that the fliQ promoter from this microorganism was able to transcribe the reporter gene uidA in a CtrA-dependent fashion in $R$. sphaeroides. Therefore, we analyzed bioinformatically the fla2 region for CtrA binding sites using the PWM obtained from studies in C. crescentus [17]; several sites were identified and its functionality was tested by site directed mutagenesis. This analysis together with the identification of the TSS of several fla2 promoters allows us to define the control region of these genes. We observed that they contain an invariant $\mathrm{A}$ at the -11 position, and a putative $\mathrm{CtrA}$ binding site near the -35 . Adenine at the -11 position could represent a relevant contact for the RNA polymerase associated with the $\sigma^{70}$ factor.
In line with this idea, it has been proposed that this nucleotide is flipped out during the open complex formation and is specifically recognized by several amino acids in the sigma-2 domain of $\sigma^{70}[43]$. In addition, we determined that a purine is located at the initiation transcription site in these four promoters, which is in agreement with previous observations in other bacterial promoters [44-46]. Therefore, several common features previously known to be relevant for transcription initiation are present in these promoters.

We centered our analysis in the divergent promoters fliL $2 p-f l i F 2 p$, and $f l g B 2 p-f l i I 2 p$ given that transcription from divergent promoters that are dependent on positive control could reveal additional features to those already known for non- divergent promoters. It is known that divergent promoters not only show a reduced space for housing the RNA polymerase and other transcription factors, but may also be affected by changes in the local superhelical density generated by the adjacent transcribing RNA complexes [47-49].

We observed that, regardless that the intercistronic region of flgB2 and fliI2 is only $47 \mathrm{bp}$ counting from the transcription start sites (TSS), there are two independent CtrA-binding sites in this region. This is supported by the fact that site-directed mutagenesis of the CtrA binding site of $f l g B 2 p$ (in the left or right element corresponding to flgB2-35 and $-27 /-28$ constructions, see Figs. 3 and 4) provoked a decrease of the activity of the reporter gene; however, mutagenesis of the $-23 /-24$ positions of $f l g B 2 p$ did not affect the expression of the reporter gene, but did affect the functional CtrA binding site of fliI $2 p$ (see Fig. 4). This suggests that binding of 


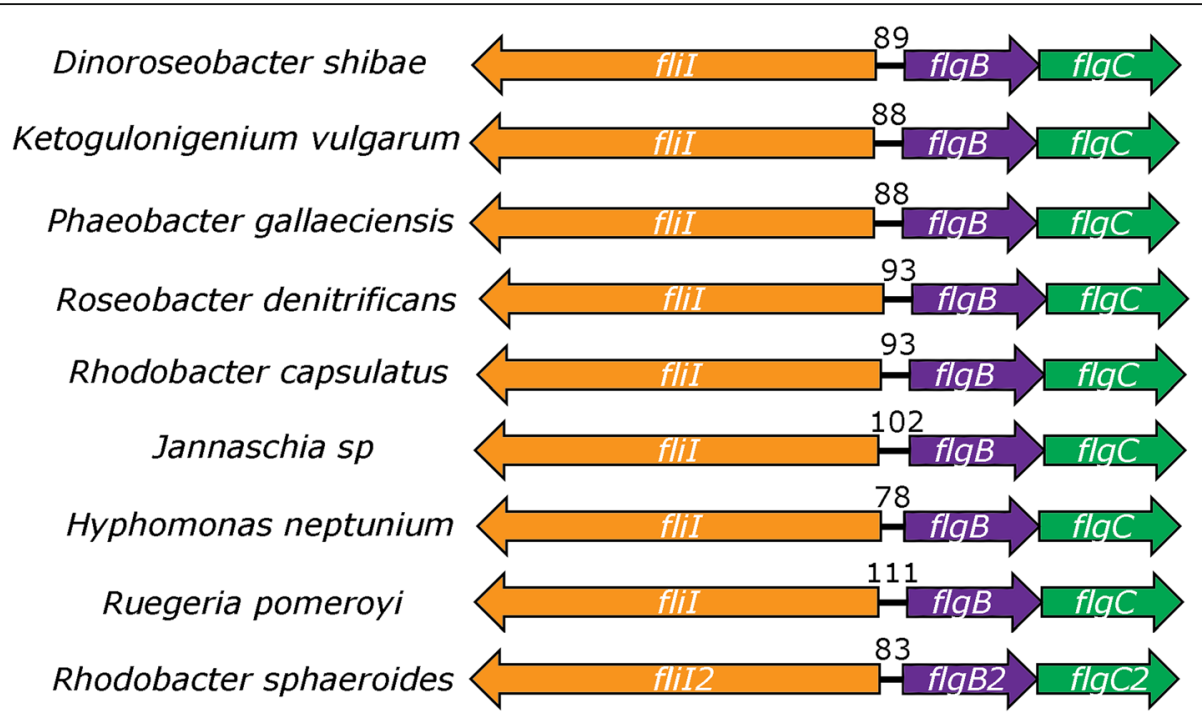

D. Shibae

GGTCATCGTCGGCCTTTCTGGTCCGTTGGATGTTCACTTACTGTTTCTAAAGGAA

TCGGGGTTAAGCGTTGGTTGAAACCATCGTGGGAGAAGCCCCGATATGAAA

K. vulgarum

GCGCATGTAAAAATCCCTCGTGATCAGCCCGGCACAACCTCTCTTTAAGGAATCAG

CCTTAAATCTTGGTTGAAACCACAAAGGAAAGCGCCCGATGCAT

P. gallaeciensis

GATCATGTTCTGGTGTCTCCAACTGTTCCTGAAAACAATTTCTAAAGGAATCGGGG

TTAAGCCTTGATTGAAATTGATCGAGGGAGAAGCCCCGGTGTTT

R. denitrificans

GGGAATCGGCTGGTTCATGTCATTCCTTTGCTTTCTGCACACTCTTTCTAAAGGAA

TCAGAGTTAAGCCTTGATGAAATCACACGAGGGAGAAGCCCGGATGTTT

R. capsulatus

CGCCATTCTGGCCCCCGTGTCTTCGGTTCGGTGTTCTTGAAACGCTTTTTAAACGA

TTCTCTCTTAAGCCTTGGTTGATAGCTCGGAGGAGAAACCCCGATGTTC

Jannaschia sp.

AGACATGGCGGATTCTCCAAACCAATCGGCGCGGGATGTGCGCCTTCATTACGGAA

TGTAAAGGAATCAGTCTTAAGCCTTCGTGTAGCCGAGATGGGAGAAGCCCAGATGTTT

H. neptunium

TGCCATGGATGCCTGCAAGTAAACAAACTCCGCATTTCTGTTAACCTGTTCTTTAG

TTAATGCGAACATTTTCCCAAAGGGTTAACCTTGGTGAAT

R. pomeroyi

TTTCAGGGCGAGGGGGTCTGGGGCCGTCATCGGGATATCTCCAACAATTTCCTGAA

AACGGTTTCTAAACGAATCGGGGTTAAGCCTTGATTGAAATTGATCGAGGGAGAAGCCCCG

ATGTTC

R. sphaeroides

GAACATCGGGGCTTCTCCCTCGATCGGTTTCACCAAGGCTTAAGGGCGATTCCTTTAGAAA GGGTAAGGCGCGAACAAAGAGGGATTTGATGTCG

Fig. 6 CtrA binding sites for the flil-flgB divergent promoters from different species. Intercistronic regions between flgB and flil of six different species of Rhodobacteraceae and one species of the Hyphomonadaceae family. These genes show a similar arrangement as that observed for flgB2 and flil2 of R. sphaeroides. The flil gene is represented in orange and flgB in violet. Below, the complete intercistronic region is shown and the sequences predicted as possible CtrA binding sites are indicated as follows: highlighted in yellow for the reverse strand, and underlined for the direct strand. For Hyphomonas neptunium two different sites are underlined given that the highest score (4) corresponds to a predicted site that is five nucleotides upstream the initiation codon of FlgB; the other possible site has a lower score (3.8) but from this localization it is likely that CtrA could activate the RNA polymerase

CtrA to activate $f l i I 2 p$ did not affect activation of $f l g B 2 p$, at least when these promoters are measured from a plasmid.

It should be stressed that the proposed CtrA-binding sites for these promoters (i.e. flgB2 $p$ and fliI $2 p$ ) do not conform to the consensus that has been previously reported for other bacteria, given that for $f \lg B 2 p$ and fliI $2 p$, the left and right elements of the CtrA binding site are located only 6 bp apart. As explained in the results section, for $f l g B 2 p$, the other possible sites for CtrA binding 
were unlikely to be functional, given that one overlapped with the TSS, and the other showed a very low score. For fliI $2 p$ the best CtrA binding site that was identified bioinformatically was not supported by the experiments reported in this work. Therefore, we presume that for these promoters CtrA is able to activate transcription from atypical binding sites. A possible scenario could be that a very short intercistronic region with divergent promoters could be particularly affected by negative supercoiling (undertwisting) of the DNA. This conformation would be due to the activity of the divergent transcription from these promoters, enabling a better recognition of the CtrA binding site regardless of the fact that the left and right elements are positioned only 6 bp apart. A similar spacing between the left and right TTAA elements of the CtrA binding site has been described for Magnetospirillum magneticum [21]. An atypical spacing between these elements was also noted for the $c t r A$ binding sites of the $\operatorname{ctr} A \mathrm{P} 1$ and $\mathrm{P} 2$ promoters of C. crescentus. In this case the P1 promoter that is negatively controlled by CtrA, could have the ungapped variant for CtrA binding; however, for the CtrA-activated P2 promoter, the contribution of the left and right elements spaced by 6 bp was verified by an electrophoretic mobility shift assays [50].

A different situation was observed for activation of $f l i F 2 p$ and $f l i L 2 p$, given that it appears that only one CtrA binding site is required for activation of these other divergent promoters. These results suggest that the CtrA binding site and both promoters must be properly placed on the same face of the DNA helix. In this regard, we identified a single CtrA binding site between the divergent promoters fliI and $f l g B$ in several species of $\alpha$-proteobacteria, suggesting that the presence of a single CtrA binding site to active divergent promoters could be a common feature. Alternatively, it is possible that the PWM does not represent the actual CtrA binding site in the regulatory regions of these bacteria, in which case other CtrA binding sites would remain to be identified.

In $C$. crescentus it has been reported that the divergent promoters $f l g B p$ and $f l i O p$, which are located 144 bp apart, share a CtrA-binding site. In this case, $f \operatorname{lgB} p$ is repressed by $\mathrm{CtrA}$ and $f l i O p$ is activated when CtrA binds to this site [27]. This difference could be the result of a different evolution of the flagellar transcriptional hierarchies. For instance, in C. cresentus the periplasmic components of the flagellum (most of the genes encoding the rod proteins, and FlgI and FlgH that form the $\mathrm{L}$ and $\mathrm{P}$ rings, respectively) are encoded by genes that are dependent on RpoN and the activator protein FlbD [9]. In $R$. sphaeroides none of its four different RpoN proteins [51] is involved in the expression of the fla2 genes (unpublished results). Moreover, the gene encoding FlbD is absent in the species of Rhodobacteraceae shown in
Fig. 6; nevertheless, other proteins of this family of activators can be identified. This information suggests that in $R$. sphaeroides and other species of this genus, the early constituents of the flagellar structure including the periplasmic components are encoded by genes that could be directly activated by CtrA.

\section{Conclusions}

In this work we show that CtrA directly activates the expression of the fla 2 genes of $R$. sphaeroides. The identification of the transcriptional start site for several fla2 promoters allowed us to identify several conserved features such as a conserved $\mathrm{A}$ at the -11 position and a purine at the initiation start site. The CtrA binding sites were tested by site directed mutagenesis and it was found that $\mathrm{CtrA}$ activates the expression of the divergent promoters fliL2p-fliFp 2 using a single binding site, whereas for the divergent promoters $f l g B 2 p$-fliI2 $p$ CtrA activates transcription from two independent sites. In addition, we found that the CtrA binding site could also be functional when the left and right elements of the full motif are $6 \mathrm{bp}$ apart.

\section{Additional file}

Additional file 1: CtrA-binding sites predicted in the fla2 cluster of Rhodobacter sphaeroides using the PWM reported for Caulobacter crescentus. Hits found by RSAT in the fla2 cluster of R. sphaeroides. (XLSX $40 \mathrm{~kb}$ )

\section{Abbreviations \\ 5'-RACE: 5'-Rapid amplification of cDNA ends; Ap: Ampicillin; BSA: Bovine serum albumin; ChIP: Chromatin immunoprecipitation; $\mathrm{Cm}$ : Chloramphenicol; EDTA: Ethylenediaminetetraacetic acid; EMSA: Gel electrophoresis mobility shift assay; Gm: Gentamycin; LB: Luria broth; MEME: Multiple EM (expectation-maximization algorithm) for Motif Elicitation; min: Minutes; MUSCLE: Multiple Sequence Comparison by Log-Expectation; Nal: Nalidixic acid; Ni-NTA: Nickel-nitrilotriacetic acid; OD600: Optical density measured at 600 nm; PBS: Phosphate buffered saline; PCR: Polymerase chain reaction; PWM: Position weight matrix; rpm: revolutions per minute; RSAT: Regulatory Sequence Analysis Tools; SD: Standard deviation; SDS: Sodium dodecyl sulfate; Spc: Spectinomycin; TCS: Two component system(s); \\ Tris: Tris(hydroxymethyl)aminomethane.; TSS: Transcriptional start site}

\section{Acknowledgments}

We thank Teresa Ballado and Javier de la Mora (IFC) for technical support, Georgina Hernandez (IIB) for valuable help with antibody production, and the Molecular Biology Unit IFC-UNAM for sequencing facilities.

\section{Funding}

This study is part of the requisites to obtain a doctoral degree by A.O. (Doctorado en Ciencias Biomédicas, Universidad Nacional Autónoma de México), who was supported during her studies by a fellowship from CONACYT. This work was partially supported by DGAPA-UNAM (PAPIITIN204317) and CONACyT (CB2014-235996).

The funding source had no role in the design of the study and collection, analysis, and interpretation of data.

Availability of data and materials

The datasets used and/or analyzed during the current study are available from the corresponding author on reasonable request. 


\section{Authors' contributions}

$L C, G D$ and SP discussed, planned and designed the experiments, AR-O performed them. LC supervised AR-O. LC and GD wrote the manuscript. Many constructions and enzymatic activities were obtained by AO. All the authors read and approved the final manuscript.

\section{Ethics approval}

Maintenance and use of the animals was in accordance with the Guidelines of the Mexican Law of Animal Protection (NOM-062-ZOO-1999). All experiments were approved by the local Institutional Animal Care and Research Advisory Committee (CICUAL, Protocol ID 146), from Universidad Nacional Autónoma de México (UNAM) and under International Laws of ethical care and use of animals (National Research Council (U.S.) et al., 2011). The mice were allowed to adapt to the new conditions for two weeks at the Animal Care Facility Unit of Instituto de Investigaciones Biomédicas, UNAM. They were housed in an individually ventilated caging system under standard conditions (mean temperature $22 \pm 2{ }^{\circ} \mathrm{C}, 40 \pm 10 \%$ relative humidity, 12:12 h light-dark cycle (lights on 7:00-19:00 h)) on sterilized wood shavings bedding (ENVIGO). They received a commercial pelletized diet (TG rodent diet T2018S.15, ENVIGO) and water ad libitum from an automated watering system

Mice were sacrificed by CO2 (according to the AVMA Guidelines for the Euthanasia of Animals 2013)

\section{Consent for publication}

Not applicable

\section{Competing interests}

The authors declare that they have no competing interest.

\section{Publisher's Note}

Springer Nature remains neutral with regard to jurisdictional claims in published maps and institutional affiliations.

Received: 5 December 2017 Accepted: 26 September 2018 Published online: 10 October 2018

\section{References}

1. Macnab RM. How bacteria assemble flagella. Annu Rev Microbiol. 2003: 57:77-100

2. Berg HC. The rotary motor of bacterial flagella. Annu Rev Biochem. $2003 \cdot 72 \cdot 19-54$

3. Smith TG, Hoover TR. Deciphering bacterial flagellar gene regulatory networks in the genomic era. Adv Appl Microbiol. 2009:67:257-95.

4. Macnab RM. Genetics and biogenesis of bacterial flagella. Annu Rev Genet. 1992:26:131-58.

5. Chevance FF, Hughes KT. Coordinating assembly of a bacterial macromolecular machine. Nat Rev Microbiol. 2008:6(6):455-65.

6. Sourjik V, Muschler P, Scharf B, Schmitt R. VisN and VisR are global regulators of chemotaxis, flagellar, and motility genes in Sinorhizobium (Rhizobium) meliloti. J Bacteriol. 2000;182(3):782-8.

7. Rotter C, Muhlbacher S, Salamon D, Schmitt R, Scharf B. Rem, a new transcriptional activator of motility and chemotaxis in Sinorhizobium meliloti. J Bacteriol. 2006;188(19):6932-42.

8. Pini F, De Nisco NJ, Ferri L, Penterman J, Fioravanti A, Brilli M, Mengoni A, Bazzicalupo M, Viollier PH, Walker GC et al: Cell cycle control by the master regulator CtrA in Sinorhizobium meliloti. PLoS Genet 2015, 11(5):e1005232.

9. Curtis PD, Brun YV. Getting in the loop: regulation of development in Caulobacter crescentus. Microbiol Mol Biol Rev. 2010;74(1):13-41.

10. Tsang J, Hoover TR. Themes and variations: regulation of RpoNdependent flagellar genes across diverse bacterial species. Scientifica (Cairo). 2014;2014:681754

11. Poggio S, Abreu-Goodger C, Fabela S, Osorio A, Dreyfus G, Vinuesa P, Camarena L. A complete set of flagellar genes acquired by horizontal transfer coexists with the endogenous flagellar system in Rhodobacter sphaeroides. J Bacteriol. 2007:189(8):3208-16.

12. Armitage JP, Macnab RM. Unidirectional, intermittent rotation of the flagellum of Rhodobacter sphaeroides. J Bacteriol. 1987:169(2):514-8.

13. de la Mora J, Uchida K, del Campo AM, Camarena L, Aizawa S, Dreyfus G. Structural characterization of the Fla2 flagellum of Rhodobacter sphaeroides. J Bacteriol. 2015;197(17):2859-66.
14. Poggio S, Osorio A, Dreyfus G, Camarena L. The flagellar hierarchy of Rhodobacter sphaeroides is controlled by the concerted action of two enhancer-binding proteins. Mol Microbiol. 2005;58(4):969-83.

15. Vega-Baray B, Domenzain C, Rivera A, Alfaro-Lopez R, Gomez-Cesar E, Poggio S, Dreyfus G, Camarena L. The flagellar set Fla2 in Rhodobacter sphaeroides is controlled by the CckA pathway and is repressed by organic acids and the expression of Fla1. J Bacteriol. 2015;197(5):833-47.

16. del Campo AM, Ballado T, de la Mora J, Poggio S, Camarena L, Dreyfus G: Chemotactic control of the two flagellar systems of Rhodobacter sphaeroides is mediated by different sets of CheY and FliM proteins. J Bacteriol 2007, 189(22):8397-8401.

17. Brilli M, Fondi M, Fani R, Mengoni A, Ferri L, Bazzicalupo M, Biondi EG. The diversity and evolution of cell cycle regulation in alpha-proteobacteria: a comparative genomic analysis. BMC Syst Biol. 2010;4:52.

18. Zhou B, Schrader JM, Kalogeraki VS, Abeliuk E, Dinh CB, Pham JQ, Cui ZZ, Dill DL, McAdams HH, Shapiro L: The global regulatory architecture of transcription during the Caulobacter cell cycle. PLoS Genet 2015, 11(1):e1004831

19. Laub MT, Chen SL, Shapiro L, McAdams HH. Genes directly controlled by CtrA, a master regulator of the Caulobacter cell cycle. Proc Natl Acad Sci U S A. 2002:99(7):4632-7.

20. Ouimet MC, Marczynski GT. Analysis of a cell-cycle promoter bound by a response regulator. J Mol Biol. 2000;302(4):761-75.

21. Greene SE, Brilli M, Biondi EG, Komeili A. Analysis of the CtrA pathway in Magnetospirillum reveals an ancestral role in motility in alphaproteobacteria. Bacteriol. 2012;194(11):2973-86.

22. Mercer RG, Callister SJ, Lipton MS, Pasa-Tolic L, Strnad H, Paces V, Beatty JT, Lang AS. Loss of the response regulator CtrA causes pleiotropic effects on gene expression but does not affect growth phase regulation in Rhodobacter capsulatus. J Bacteriol. 2010:192(11):2701-10.

23. Francez-Charlot A, Kaczmarczyk A, Vorholt JA. The branched CcsA/CckAChpT-CtrA phosphorelay of Sphingomonas melonis controls motility and biofilm formation. Mol Microbiol. 2015;97(1):47-63.

24. De Nisco NJ, Abo RP, Wu CM, Penterman J, Walker GC: Global analysis of cell cycle gene expression of the legume symbiont Sinorhizobium meliloti. Proc Natl Acad Sci U S A 2014, 111(9):3217-3224.

25. Barnett MJ, Hung DY, Reisenauer A, Shapiro L, Long SR. A homolog of the CtrA cell cycle regulator is present and essential in Sinorhizobium meliloti. J Bacteriol. 2001;183(10):3204-10.

26. Brassinga AK, Siam R, McSween W, Winkler H, Wood D, Marczynski GT. Conserved response regulator CtrA and IHF binding sites in the alphaproteobacteria Caulobacter crescentus and Rickettsia prowazekii chromosomal replication origins. J Bacteriol. 2002;184(20):5789-99.

27. Boyd $\mathrm{CH}$, Gober JW. Temporal regulation of genes encoding the flagellar proximal rod in Caulobacter crescentus. J Bacteriol. 2001;183(2):725-35.

28. Jones SE, Ferguson NL, Alley MR. New members of the ctrA regulon: the major chemotaxis operon in Caulobacter is CtrA dependent. Microbiology. 2001;147(Pt 4):949-58

29. Belas R, Horikawa E, Aizawa S, Suvanasuthi R. Genetic determinants of Silicibacter sp. TM1040 motility. J Bacteriol. 2009;191(14):4502-12.

30. Sistrom WR. The kinetics of the synthesis of photopigments in Rhodopseudomonas sphaeroides. J Gen Microbiol. 1962;28:607-16.

31. Ausubel FM, Brent R, Kingston RE, Moore DD, Seidman JG, Smith JA, Struh K. Current protocols in molecular biology. New York: John Wiley; 1987.

32. Quandt J, Hynes MF. Versatile suicide vectors which allow direct selection for gene replacement in gram-negative bacteria. Gene. 1993;127(1):15-21.

33. Davis J, Donohue TJ, Kaplan S. Construction, characterization, and complementation of a Puf- mutant of Rhodobacter sphaeroides. J Bacteriol. 1988;170(1):320-9.

34. Jefferson RA, Burgess SM, Hirsh D. B-Glucuronidase from Escherichia coli as a gene-fusion marker. Proc Natl Acad Sci U S A. 1986;83(22):8447-51.

35. Hernandez-Valle J, Domenzain C, de la Mora J, Poggio S, Dreyfus G, Camarena L. The Master Regulators of the Fla1 and Fla2 Flagella of Rhodobacter sphaeroides Control the Expression of Their Cognate CheY Proteins. J Bacteriol. 2017;199(5).

36. Kunkel TA. Rapid and efficient site-specific mutagenesis without phenotypic selection. Proc Natl Acad Sci U S A. 1985;82(2):488-92.

37. Harlow E, Lane D: Antibodies. A Laboratory Manual. Cold Spring Harbor, New York:: Cold Spring Harbor Laboratory Press.; 1988.

38. Schneider CA, Rasband WS, Eliceiri KW. NIH image to ImageJ: 25 years of image analysis. Nat Methods. 2012;9(7):671-5. 
39. Edgar RC. MUSCLE: multiple sequence alignment with high accuracy and high throughput. Nucleic Acids Res. 2004;32(5):1792-7.

40. Porter SL, Wilkinson DA, Byles ED, Wadhams GH, Taylor S, Saunders NJ, Armitage JP. Genome sequence of Rhodobacter sphaeroides strain WS8N. J Bacteriol. 2011;193(15):4027-8.

41. Lang AS, Beatty JT. A bacterial signal transduction system controls genetic exchange and motility. J Bacteriol. 2002;184(4):913-8.

42. Wang H, Ziesche L, Frank O, Michael V, Martin M, Petersen J, Schulz S, Wagner-Dobler I, Tomasch J. The CtrA phosphorelay integrates differentiation and communication in the marine alphaproteobacterium Dinoroseobacter shibae. BMC Genomics. 2014;15:130.

43. Feklistov A, Darst SA. Structural basis for promoter-10 element recognition by the bacterial RNA polymerase sigma subunit. Cell. 2011;147(6):1257-69.

44. Hawley DK, McClure WR. Compilation and analysis of Escherichia coli promoter DNA sequences. Nucleic Acids Res. 1983:11(8):2237-55.

45. Vvedenskaya IO, Zhang Y, Goldman SR, Valenti A, Visone V, Taylor DM, Ebright RH, Nickels BE. Massively systematic transcript end readout, "MASTER": transcription start site selection, transcriptional slippage, and transcript yields. Mol Cell. 2015;60(6):953-65.

46. Prados J, Linder P, Redder P. TSS-EMOTE, a refined protocol for a more complete and less biased global mapping of transcription start sites in bacterial pathogens. BMC Genomics. 2016;17(1):849.

47. Liu LF, Wang JC. Supercoiling of the DNA template during transcription. Proc Natl Acad Sci U S A. 1987;84(20):7024-7.

48. Opel ML, Hatfield GW. DNA supercoiling-dependent transcriptional coupling between the divergently transcribed promoters of the ilvYC operon of Escherichia coli is proportional to promoter strengths and transcript lengths. Mol Microbiol. 2001;39(1):191-8

49. Zhi X, Dages S, Dages K, Liu Y, Hua ZC, Makemson J, Leng F. Transient and dynamic DNA supercoiling potently stimulates the leu-500 promoter in Escherichia coli. J Biol Chem. 2017;292(35):14566-75.

50. Spencer W, Siam R, Ouimet MC, Bastedo DP, Marczynski GT. CtrA, a global response regulator, uses a distinct second category of weak DNA binding sites for cell cycle transcription control in Caulobacter crescentus. J Bacteriol. 2009:191(17):5458-70.

51. Poggio S, Osorio A, Dreyfus G, Camarena L. The four different $\sigma^{54}$ factors of Rhodobacter sphaeroides are not functionally interchangeable. Mol Microbiol. 2002;46(1):75-85.

52. Sockett RE, Foster JCA, Armitage JP. Molecular biology of the Rhodobacter sphaeroides flagellum. FEMS Symp. 1990;53:473-9.

53. Simon R, Priefer U, Pühler A. A broad host range mobilization system for in vivo genetic engineering: transposon mutagenesis in gram negative bacteria. Bio/Technology. 1983;1:37-45.

54. Keen NT, Tamaki S, Kobayashi D, Trollinger D. Improved broad-host-range plasmids for DNA cloning in gram-negative bacteria. Gene. 1988;70(1):191-7.

55. Metcalf WW, Wanner BL. Construction of new $\beta$-glucuronidase cassettes for making transcriptional fusions and their use with new methods for allele replacement. Gene. 1993;129(1):17-25.

Ready to submit your research? Choose BMC and benefit from:

- fast, convenient online submission

- thorough peer review by experienced researchers in your field

- rapid publication on acceptance

- support for research data, including large and complex data types

- gold Open Access which fosters wider collaboration and increased citations

- maximum visibility for your research: over $100 \mathrm{M}$ website views per year

At BMC, research is always in progress.

Learn more biomedcentral.com/submissions 